\title{
Static and Fatigue Behavior of Adhesive Joints in SMC-SMC Composites
}

\author{
S. K. MAZUMDAR* and P. K. MALLICK \\ Department of Mechanical Engineering \\ University of Michigan - Dearborn \\ Dearborn, Michigan 48128
}

\begin{abstract}
This paper discusses the static and fatigue behavior of adhesively bonded single lap joints in SMC-SMC composites. Effects of lap length and adhesive thickness on the static and fatigue strength of SMC-SMC adhesive joints are studied. Effects of SMC surface preparation and test speed on the joint performance are evaluated. Finally, the effect of water exposure on the joint durability is also investigated. Results show that the static behavior of adhesive joints in SMC-SMC composites is significantly influenced by the lap length and adhesive thickness. With an increase in lap length from $12.7 \mathrm{~mm}$ to $38.1 \mathrm{~mm}$, the joint failure load increases by $37 \%$. The joint failure load also increases with the adhesive thickness, but it reaches a maximum at an adhesive thickness of $0.33 \mathrm{~mm}$ and then decreases. However, lap length and adhesive thickness have negligible effect on the ratio of fatigue strength to static strength. The fatigue strength at $10^{6}$ cycles is approximately $50 \%$ to $54 \%$ of the static strength for various adhesive thicknesses and lap lengths investigated in this study. Adhesive failure, fiber tear or combination of these two failure modes are observed during both static and fatigue tests.
\end{abstract}

\section{ITTRODUCTION}

$\mathrm{W}$ ith increasing use of sheet molding compound (SMC) composites in the automotive and other durable goods industries, it is becoming important to develop design data for joints in these materials. To utilize bonded joints efficiently and reliably, a complete understanding of the failure mechanism under different loading conditions is also needed. Numerous reports and journal articles are available delineating the adhesive joint properties of laminated composites, particularly with carbon fiber/epoxy laminates (1-4). A literature survey on SMC indicates that static and fatigue data of adhesive joints in SMC composites are extremely limited. Dillard and Spinu (5) studied the durability of adhesive joints between SMC and aluminum joints. The adhesive used was based on a urethane. Specimens were exposed either to an environmental cycle or to fixed conditions of temperature and humidity for a period of seven days, with or without a constant load. They observed that the metal surface treatment has a significant influence on the durability of these joints. Krause, Holubka, and Chun (6) determined the fatigue properties of adhesive joints in a random fiber sheet molding com-

*Currently with Plascore Inc., Zeeland, Mich. pound composite (HMC) as well as a continuous fiber sheet molding compound composite (XIMC). Both urethane and epoxy/polyamide adhesives were used. Exposure to moisture was found to cause one to three orders of magnitude reductions in fatigue life at fatigue stress levels approximating $50 \%$ of the static strength. The higher reduction was obtained when the exposure to moisture was at $90^{\circ} \mathrm{C}$. Effects of corrosive environments on the fatigue strength of adhesive joints between SMC and steel have been investigated by Holubka et al. (7). The durability of adhesive bonds between SMC and steel is greatly influenced by the primer used on the steel surface. Three to four orders of magnitude reduction in fatigue life is observed for adhesive bonds exposed to water prior to fatigue testing.

There is no reported systematic study that examines the static and fatigue performance of adhesively bonded joints between SMC-SMC substrates. Yet, many structural applications in the automotive and other industries may involve such joints, and furthermore, many of these structures may experience repeated loading in service. The current experimental work was undertaken to study the effects of two important joint design parameters, namely the overlap length and the adhesive thickness on the static and fatigue behavior of SMC-SMC adhesive joints. Effects of various surface preparation, crosshead speed, and moisture absorp- 
tion are investigated. In addition to the continuous bonding, the effect of recessing on the joint strength is also investigated. The recessed joints are made with adhesive at each end of the lap and a gap in the center portion of the lap in the single lap joint.

\section{EXPERMETTAL PROCEDURE}

\section{Material}

The material used as substrate in this study is a sheet molding compound (SMC) composite containing randomly oriented short E-glass fibers in a general purpose vinyl ester resin. The nominal fiber content was 25-30wt \%. The compression molded SMC plates, supplied by the Automotive Composites Consortium (ACC), were $355 \mathrm{~mm} \times 355 \mathrm{~mm} \times 2.5-2.8 \mathrm{~mm}$ (thickness) in size. The adhesive used was a one-component reformulated epoxy adhesive, which was supplied in two batches by ACC. It is an experimental adhesive and is not commercially available at this time.

\section{Characterization of SMC Plates}

Tensile properties of the SMC were measured in two mutually perpendicular directions, parallel to the adjoining edges of the molded plates. These two directions were marked $A$ and $B$ in the molded plates. Tensile strengths in the $\mathrm{A}$ and $\mathrm{B}$ directions were found to be $120.7 \pm 11.24 \mathrm{MPa}$ and $41.93 \pm 77.72 \mathrm{MPa}$, respectively. These results were the average of nine dogbone specimens along the A direction taken from plate 1 and nine dogbone specimens along the $\mathrm{B}$ direction taken from plate 2 . In another set of tests, both $A$ and $B$ direction specimens were taken from each of the three plates considered. In this set, the tensile strength was $104 \pm 9 \mathrm{MPa}$ for the A direction specimens and $32.1 \pm 1.9 \mathrm{MPa}$ for the B-direction specimens. Thus, both sets of data show nearly a 3-to- 1 tensile strength difference in the $\mathrm{A}$ and $\mathrm{B}$ directions. This indicates that the fiber orientation in the SMC plates is not truly random, perhaps because of the charge pattern used in molding these plates.

\section{Preparation of Bonded Specimens}

Single lap joints with various adhesive thickness and lap lengths were prepared as shown in Fig. 1. Lap lengths were either $12.7,25.4$, or $38.1 \mathrm{~mm}$, and the adhesive thickness was varied between 0.127 and $1.651 \mathrm{~mm}$. The lap width was $25.4 \mathrm{~mm}$. Unless otherwise specified, the substrates were taken in the A direction of the SMC plates. A few B-direction substrates were also used. The adhesive thickness was controlled using steel shims and a specially designed fixture. Except for a few specimens, the joining areas in the substrates were simply wiped with a clean dry rag before applying the adhesive. In order to investigate the effect of SMC surface preparation, a few specimen surfaces were either acetone cleaned or sanded with a 60 grit sand paper followed by a 150 grit sand paper. Care was taken to wipe off excess adhesive from the sides of the joint. The adhesive was applied

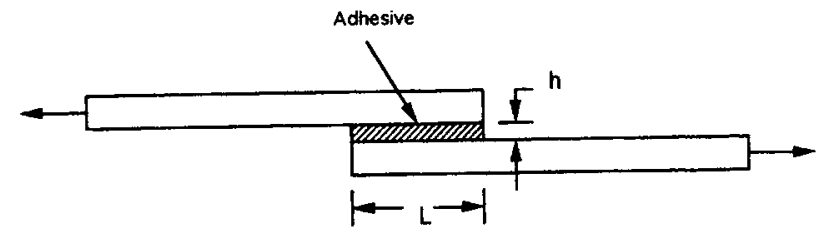

(a) Continuous Single Lap Joint

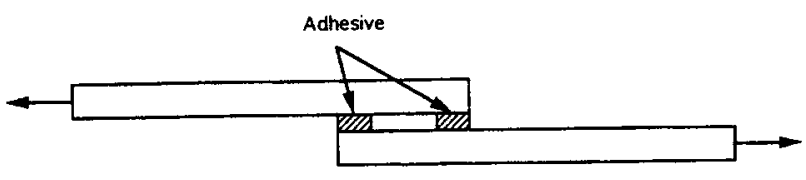

(b) Recessed Single Lap Joint

Fig. 1. Single lap joints in SMC: (a) continuous, (b) recessed.

in the lap area and was cured in an air circulating oven at $121^{\circ} \mathrm{C}$ for $45 \mathrm{~min}$ following the procedure recommended by the adhesive manufacturer. A small weight was placed on the top substrate to maintain a uniform pressure normal to the lap area during the curing stage. The joining areas of a few specimens were examined using a low power magnification after they were statically tested to failure. The adhesive that remained bonded to one of the substrates after the joint failure was virtually void-free. The SMC surface was relatively smooth.

\section{Test Procedure}

Specimens were tested at room temperature and ambient condition in a computer controlled MTS servohydraulic testing machine. A special fixture for gripping the specimen was designed to make sure that the loading direction passes through the center line of the adhesive. Most of the static tests were conducted at a crosshead speed of $1.27 \mathrm{~mm} / \mathrm{min}$. The peak load was recorded for each case. The lap shear value was calculated by dividing the peak load with the lap area, which is the product of the lap width and the lap length as shown in Fig. 1. Load-controlled tensiontension fatigue tests were conducted at room temperature and ambient condition at a cycling frequency of $10 \mathrm{~Hz}$. The load ratio $\left(P_{\min } / P_{\max }\right)$ was +0.1 .

\section{STATIC TEST RESULTS}

\section{Efiecte of Surface Preparation and Crosshead Speed}

Dry cleaned surfaces, acetone cleaned surfaces, and sanded surfaces were used to determine the effect of surface preparation on the joint strength. The lap length and adhesive thickness were 12.7 and 0.762 $\mathrm{mm}$, respectively. Tests were conducted at three different crosshead speeds, namely $1.27,12.7$, and 25.4 $\mathrm{mm} / \mathrm{min}$ to examine the effect of strain rate. Test results with average values and standard deviations are 
Table 1. Effect of Surface Preparation and Crosshead Speed on the Peak Load. (Lap length = $12.7 \mathrm{~mm}$. Adhesive thickness $=0.762 \mathrm{~mm}$.)

\begin{tabular}{ccrr}
\hline $\begin{array}{c}\text { Crosshead } \\
\text { Speed } \\
(\mathrm{mm} / \mathrm{min})\end{array}$ & $\begin{array}{c}\text { Dry Cleaned } \\
\text { Surfaces }\end{array}$ & $\begin{array}{c}\text { Acetone Cleaned } \\
\text { Surfaces }\end{array}$ & $\begin{array}{c}\text { Sanded } \\
\text { Surfaces }\end{array}$ \\
\hline 1.27 & $2.03 \pm 0.07 \mathrm{kN}$ & $2.01 \pm 0.03 \mathrm{kN}$ & $2.29 \pm 0.20 \mathrm{kN}$ \\
& $(454.95 \pm 15.45 \mathrm{lb})$ & $(451.24 \pm 5.77 \mathrm{lb})$ & $(513.5 \pm 44.96 \mathrm{lb})$ \\
\hline 12.7 & $2.52 \pm 0.20 \mathrm{kN}$ & $2.56 \pm 0.26 \mathrm{kN}$ & $2.24 \pm 0.21 \mathrm{kN}$ \\
& $(565.3 \pm 45.63 \mathrm{lb})$ & $(575.6 \pm 58.08 \mathrm{lb})$ & $(502.44 \pm 46.91 \mathrm{lb})$ \\
\hline 25.4 & $2.64 \pm 0.28 \mathrm{kN}$ & $2.69 \pm 0.18 \mathrm{kN}$ & $2.41 \pm 0.11 \mathrm{kN}$ \\
& $(592.48 \pm 62.06 \mathrm{lb})$ & $(604.8 \pm 41.34 \mathrm{lb})$ & $(541.99 \pm 24.4 \mathrm{lb})$ \\
\hline
\end{tabular}

shown in Table 1. Four to five tests were conducted for each case. Observations made from this Table are as follows:

1) The peak load at which joint failure occurs increases with increasing crosshead speed, an indication of the strain rate effect on the joint strength.

2) The peak load for both dry cleaned and acetone cleaned surfaces increases by about $30 \%$ for an increase in the crosshead speed from 1.27 to 25.4 $\mathrm{mm} / \mathrm{min}$. At any crosshead speed, the difference in peak load for the dry cleaned and acetone cleaned surfaces is very small. Sanding the lap area prior to bonding gives a higher peak load at the lowest crosshead speed; however, the peak load is lower than both dry cleaned and acetone cleaned surfaces at higher crosshead speeds.

\section{Efrecte of Adhosive Thicknoss and Lap Length}

Figure 2 shows the effects of both adhesive thickness $(h)$ as well as lap length $(L)$ on the peak load. The load carrying capacity first increases with an increase in adhesive thickness from $0.127 \mathrm{~mm}$ to $0.33 \mathrm{~mm}$,

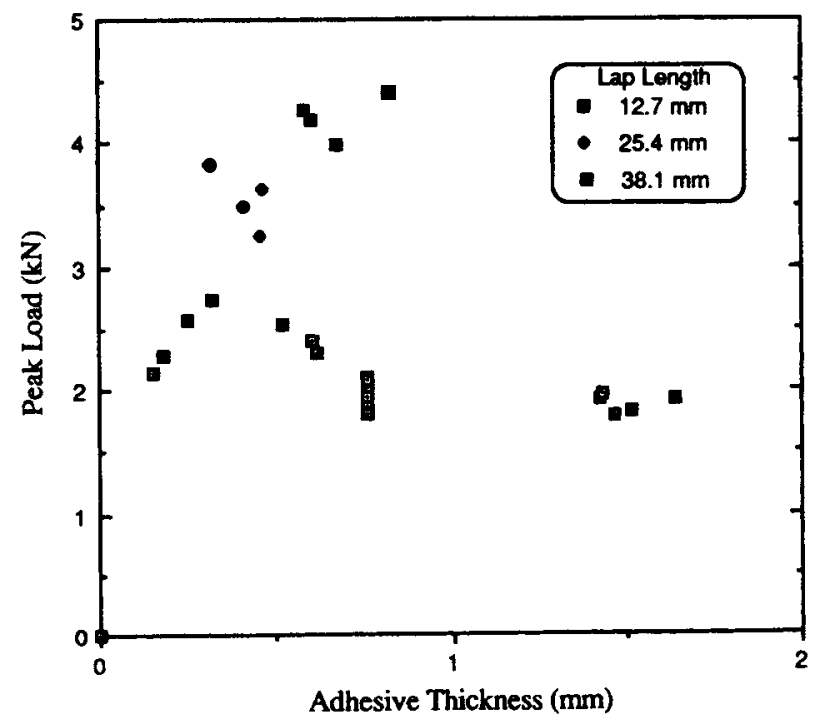

Fig. 2. Peak static load vs. adhesive thickness for continuous SMC-SMC lap joints. and then decreases with increasing adhesive thickness. However, the peak load levels off to a constant value above an adhesive thickness of $0.762 \mathrm{~mm}$. The maximum peak load in the present case was obtained with $0.33 \mathrm{~mm}$ adhesive thickness. At the lower thickness range $(0.127-0.254 \mathrm{~mm})$, most of the specimens failed by adhesive failure (Fig. $3 a$ ). A combination of adhesive failure and fiber tear was found in the thickness range of $0.254 \mathrm{~mm}$ to $0.584 \mathrm{~mm}$ (Fig. $3 b$ ). By increasing the adhesive thickness above $0.762 \mathrm{~mm}$, the failure was found to be mostly due to fiber tear (Fig. $3 c$. Near an adhesive thickness of $1.27 \mathrm{~mm}$, deep fiber tear was observed (Fig. 3d).

Figure 2 also shows the effect of lap length on the peak load, which increases with increasing lap length. However as shown in Fig. 4, the lap shear value, obtained by dividing the peak load with the lap area, is much lower for the $25.4 \mathrm{~mm}$ and $38.1 \mathrm{~mm}$ lap lengths than for the $12.7 \mathrm{~mm}$ lap length. Figure 5 shows the lap shear value as a function of $L / h$ ratio. For the $12.7 \mathrm{~mm}$ lap length, there is a distinct maximum in the lap shear value that occurs at an $\mathrm{L} / \mathrm{h}$ ratio of 45 for the SMC-SMC joints investigated here. The effect of increasing lap length can also be seen in Fig. 5 .

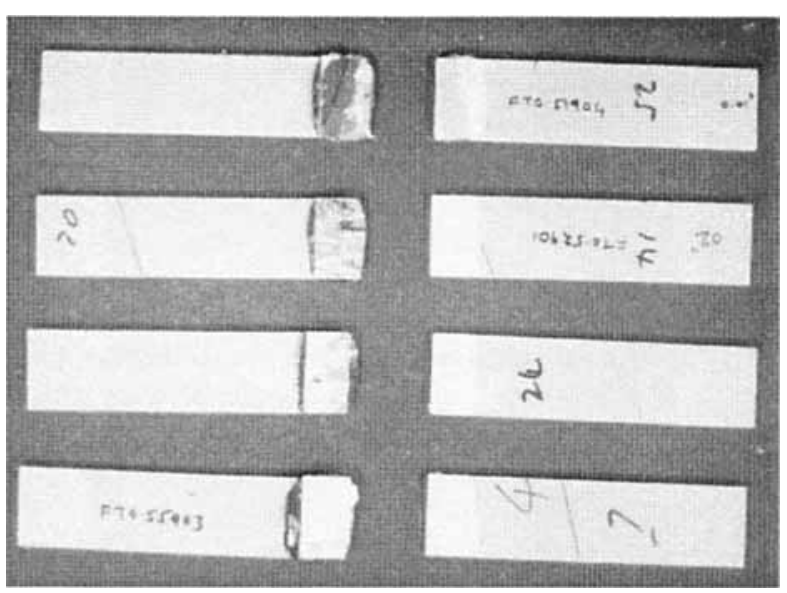

Fig. 3. Failure modes observed in SMC-SMC lap joints with lap length $=12.7 \mathrm{~mm}$ and adheswe thickness (a) $0.254 \mathrm{~mm}$, (b) $0.508 \mathrm{~mm}$, (c) $0.762 \mathrm{~mm}$ and (d) $1.27 \mathrm{~mm}$. 


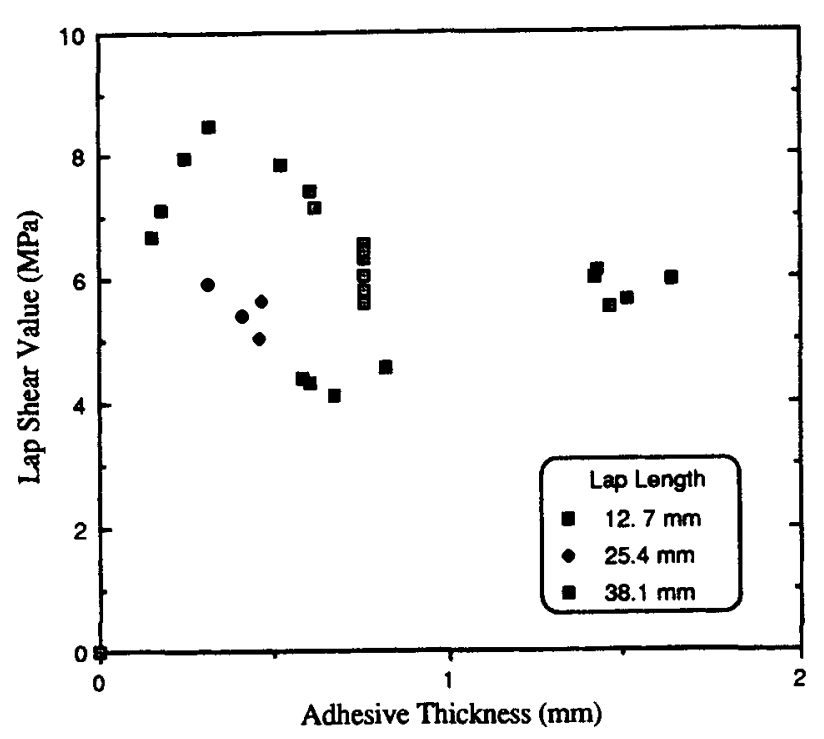

Fig. 4. Lap shear value us. adhesive thickness for SMC-SMC lap joints.

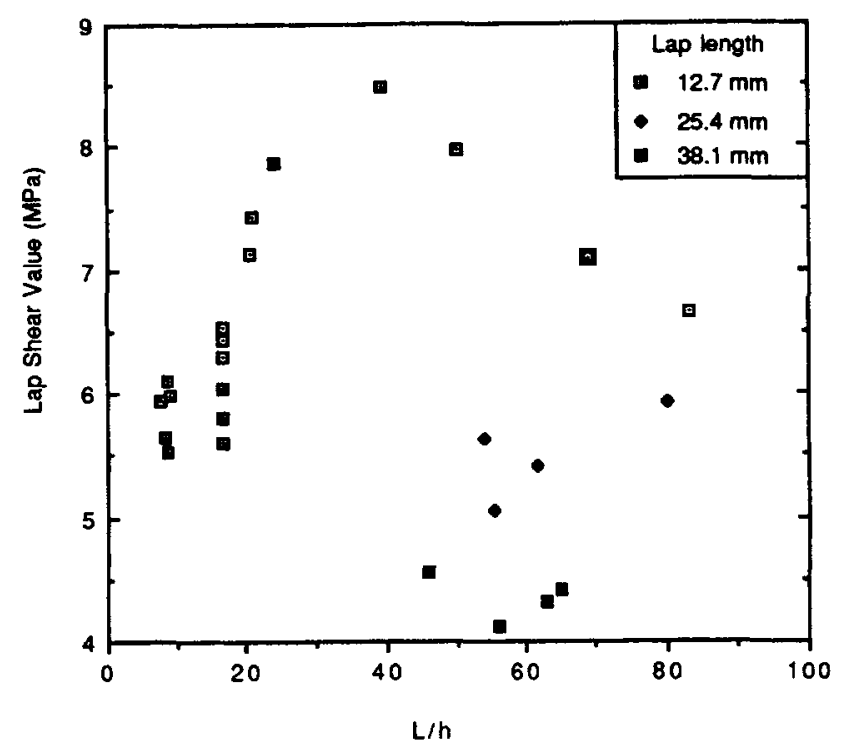

Fig. 5. Lap shear value us. $L / h$ ratio for SMC-SMC lap joints.

\section{A-direction w. B direction Joint Strengths}

It was mentioned earlier that the substrate tensile strength in the B direction is nearly three times lower than that in the A direction. In order to investigate the effect of substrate directionality on the adhesive joint strength, seven bonded specimens were prepared with the $\mathrm{B}$ direction parallel to the loading direction. The lap length and adhesive thickness in these specimens were $12.7 \mathrm{~mm}$ and $0.762 \mathrm{~mm}$, respectively.

The joint strength in the $B$ direction was found to be slightly lower than that in the A direction. Out of the seven specimens tested in the B-direction, three specimens failed by stock break (i.e. tensile failure across the width of one of the SMC substrates) and the remaining four failed by $100 \%$ fiber tear. Out of the three stock breaks, two had substrate failure very close to the joint and one failed $38.1 \mathrm{~mm}$ away from the joint.

Disregarding the three specimens with stock break, the joint peak load in the B-direction was $1.925 \pm$ $0.175 \mathrm{kN}$ compared to the A direction joint peak load of $2.024 \pm 0.069 \mathrm{kN}$. The three specimens with stock break failed at a peak load of $1.784 \pm 0.312 \mathrm{kN}$. The tensile stress corresponding to this failure load is $27.65 \pm 4.83 \mathrm{MPa}$, which is close to the B-direction tensile strength of this SMC.

\section{Continuous ve. Recessed Joints}

The static test data discussed so far included a continuous layer of adhesive. Several single lap specimens were prepared with adhesive at each end of the lap and a gap or recess in the center portion of the lap. The total lap length was $50.8 \mathrm{~mm}$; however, the adhesive was only over a length of $12.7 \mathrm{~mm}$ at each end, and thus, the gap was $25.4 \mathrm{~mm}$. Several specimens were also prepared at the same time with a continuous $50.8 \mathrm{~mm}$ adhesive layer in the lap. The static peak load with the recessed joint was $4.66 \pm 0.66 \mathrm{kN}$ and that of the continuous joint was $4.72 \pm 0.34 \mathrm{kN}$. Thus, both recessed and continuous joints had equal static failure loads. Interestingly, when an average lap shear value based on the net lap shear area is calculated, the recessed joint gives a lap shear value of $7.23 \pm 1.02 \mathrm{MPa}$ compared to $3.66 \pm 0.26 \mathrm{MPa}$ for the continuous joint.

\section{Discussion on Static Test Results}

Failure in SMC-SMC joints in static tests occurred mostly by fiber tear or delamination which initiates at one of the lap ends slightly below the surface of one of the substrates. Fiber tear propagates almost parallel to the joint, always remaining close to the surface of the substrate in which it is first initiated. This type of failure in the substrate can be attributed to high peel stress acting in the thickness direction of the substrate. The peel stress is a tensile normal stress at the lap ends and has the highest value at these locations. Finite element analysis of SMC-SMC lap joints (8) shows that the maximum peel stress in the substrate decreases with increasing lap length, but increases with increasing adhesive thickness. This may explain the reason for increasing failure load with increasing lap length and decreasing failure load with increasing adhesive thickness. Furthermore, finite element analysis of recessed joints (9) shows that recessing does not significantly increase the stresses at the lap ends and the peel stress at the recess ends are compressive in nature. This may explain the reason for obtaining static failure loads in recessed SMC-SMC joints that are as high as in continuous SMC-SMC joints. 
Table 2. Static Test Results for the Specimen Batch Prepared for Fatigue Tests.

\begin{tabular}{|c|c|c|c|}
\hline $\begin{array}{l}\text { Lap Length } \\
\text { (mm) }\end{array}$ & $\begin{array}{l}\text { Adhesive Thickness } \\
\text { (mm) }\end{array}$ & $\begin{array}{l}\text { Peak Load } \\
(\mathbf{k N})\end{array}$ & Failure Mode(1) \\
\hline $\begin{array}{l}12.7 \\
12.7 \\
12.7 \\
12.7\end{array}$ & $\begin{array}{l}0.762 \\
0.762 \\
0.762 \\
0.762\end{array}$ & $\begin{array}{l}2.31 \\
2.63 \\
2.61 \\
2.72\end{array}$ & $\begin{array}{l}36.6 \% \mathrm{FT}, 63.4 \% \mathrm{ADH} \\
30 \% \mathrm{FT}, 70 \% \mathrm{ADH} \\
90 \% \mathrm{FT}, 10 \% \mathrm{ADH} \\
88.4 \% \mathrm{FT}, 11.6 \% \mathrm{ADH}\end{array}$ \\
\hline $\begin{array}{l}38.1 \\
38.1 \\
38.1\end{array}$ & $\begin{array}{l}0.762 \\
0.762 \\
0.762\end{array}$ & $\begin{array}{l}\text { Avg. }=2.57 \pm 0.18 \\
4.05 \\
3.58 \\
3.25\end{array}$ & $\begin{array}{l}100 \% \mathrm{FT} \\
39.4 \% \mathrm{FT}, 60.6 \% \mathrm{ADH} \\
31.3 \% \mathrm{FT}, 68.7 \% \mathrm{ADH}\end{array}$ \\
\hline $\begin{array}{l}12.7 \\
12.7 \\
12.7\end{array}$ & $\begin{array}{l}1.27 \\
1.27 \\
1.27\end{array}$ & $\begin{array}{l}\text { Avg. }=3.63 \pm 0.40 \\
2.27 \\
1.95 \\
2.00\end{array}$ & $\begin{array}{l}45 \% \text { FT, } 55 \% \text { ADH } \\
100 \% \text { FT } \\
100 \% \text { FT }\end{array}$ \\
\hline & & Avg. $=2.07 \pm 0.17$ & \\
\hline
\end{tabular}

Table 3. Summary of Fatigue Test Results.

\begin{tabular}{|c|c|c|c|c|}
\hline $\begin{array}{c}\text { Lap } \\
\text { Length } \\
(\mathbf{m m})\end{array}$ & $\begin{array}{c}\text { Adhesive } \\
\text { Thickness } \\
\text { (mm) }\end{array}$ & $\begin{array}{l}\text { Ratio of Fatigue Load } \\
\text { to Avg. Peak Static Load(1) } \\
\text { (\%) }\end{array}$ & $\begin{array}{l}\text { Cycles } \\
\text { to Failure }\end{array}$ & $\begin{array}{l}\text { Failure } \\
\text { Mode(2) }\end{array}$ \\
\hline 12.7 & 0.762 & $\begin{array}{l}71 \\
70 \\
69.8 \\
69 \\
64.4 \\
61.7 \\
58.5 \\
57.7 \\
57.7 \\
57.2 \\
54.2 \\
49.9 \\
49.2 \\
33.6\end{array}$ & $\begin{array}{r}32,446 \\
533 \\
3943 \\
33,199 \\
2441 \\
502,643 \\
487,093 \\
1,766,863 \\
1,855,638 \\
518,609 \\
>3,413,000 \\
>3,204,000 \\
>4,184,325 \\
>4,000,000\end{array}$ & $\begin{array}{l}71.6 \% \mathrm{FT}, 28.4 \% \mathrm{ADH} \\
100 \% \mathrm{FT} \\
88.3 \% \mathrm{FT}, 11.7 \% \mathrm{ADH} \\
100 \% \mathrm{FT} \\
100 \% \mathrm{FT} \\
68.3 \% \mathrm{FT}, 31.7 \% \mathrm{ADH} \\
48.3 \% \mathrm{FT}, 51.7 \% \mathrm{ADH} \\
90 \% \mathrm{FT}, 10 \% \mathrm{ADH} \\
100 \% \mathrm{FT} \\
100 \% \mathrm{FT} \\
\text { Did not fail } \\
\text { Did not fail } \\
\text { Did not fail } \\
\text { Did not fail }\end{array}$ \\
\hline 38.1 & 0.762 & $\begin{array}{l}\mathbf{5 9 . 5} \\
\mathbf{5 9} \\
\mathbf{5 7 . 5} \\
\mathbf{5 1 . 9} \\
\mathbf{5 0 . 2}\end{array}$ & $\begin{array}{r}333,351 \\
7057 \\
>4,357,500 \\
>4,240,000 \\
1,705,957\end{array}$ & $\begin{array}{l}100 \% \mathrm{FT} \\
16 \% \mathrm{FT}, 84 \% \mathrm{ADH} \\
\text { Did not fail } \\
\text { Did not fail } \\
95.8 \% \mathrm{FT}, 4.2 \% \mathrm{ADH}\end{array}$ \\
\hline 12.7 & 1.27 & $\begin{array}{l}76.5 \\
76.1 \\
76.1 \\
61.9 \\
61.8 \\
55.5\end{array}$ & $\begin{array}{r}11,572 \\
80,897 \\
1818 \\
>5,000,000 \\
423,119 \\
>4,959,000\end{array}$ & $\begin{array}{l}91.6 \% \mathrm{FT}, 8.4 \% \mathrm{ADH} \\
100 \% \mathrm{FT} \\
100 \% \mathrm{FT} \\
\text { Did not fail } \\
90 \% \mathrm{FT}, 10 \% \mathrm{ADH} \\
\text { Did not fail }\end{array}$ \\
\hline
\end{tabular}

(1) Average peak static loads are given in Table 2.

(2) FT: fiber tear, $A D H$ : adhesive failure.

\section{FATIGUE TEST RRSULTS}

\section{Bifects of Joint Parmeters}

In order to examine the effect of joint design parameters on the fatigue strength, three different groups of fatigue specimens were prepared using the joint preparation procedure described earlier. They were (i) $12.7 \mathrm{~mm}$ lap length, $0.762 \mathrm{~mm}$ adhesive thickness, (ii) $38.1 \mathrm{~mm}$ lap length, $0.762 \mathrm{~mm}$ adhesive thickness and (iii) $12.7 \mathrm{~mm}$ lap length, $1.27 \mathrm{~mm}$ adhesive thickness. For each group of specimens, static tension tests were first performed to determine the average peak load (see Table 2). The adhesive used in these specimens came from the second batch and was found to be of thicker consistency than the first batch used in the first part of this work. Moreover, as can be seen in Table 2, the second batch of adhesive gave higher peak load than the first batch. 


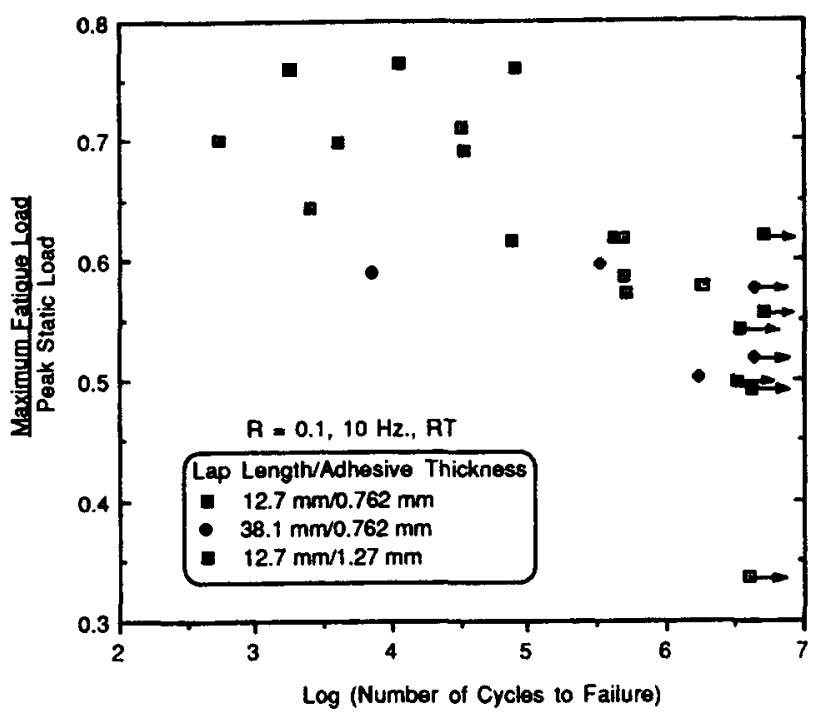

Fig. 6. Fatigue S-N diagram for SMC-SMC lap joints.

Fatigue test results are given in Table 3 and plotted in Fig. 6 with the ratio of maximum fatigue (cyclic) load to peak static load vs. the number of cycles to failure. The following observations can be made from the fatigue test results.

(a) $12.7 \mathrm{~mm}$ lap length and $0.762 \mathrm{~mm}$ adhesive thickness

A total of 15 fatigue tests were conducted for this group of specimens. The maximum fatigue load applied was varied between $33.6 \%$ and $71 \%$ of the peak static load. At maximum load equal to or lower than $54 \%$ of the peak static load, failure did not occur for $3.0 \times 10^{6}$ cycles and tests were discontinued if no failure occurred between 3 to $4.2 \times 10^{6}$ cycles. The fatigue load at $10^{6}$ cycles is estimated as $1.393 \mathrm{kN}$, which is $54.2 \%$ of peak static load of $2.57 \mathrm{kN}$.

(b) $38.1 \mathrm{~mm}$ lap length and $0.762 \mathrm{~mm}$ adhesive thickness

A total of five fatigue tests were conducted at various load amplitudes for this group of specimens. The fatigue load at $10^{6}$ cycles is estimated as $1.819 \mathrm{kN}$, which is $50.2 \%$ of peak static load of $3.625 \mathrm{kN}$. In terms of load carrying capacity, the increase in lap length from 12.7 to $38.1 \mathrm{~mm}$ increases the fatigue load from $1.347 \mathrm{kN}$ to $1.819 \mathrm{kN}$, which is a $35 \%$ increase. However, for both lap lengths, the ratios of maximum fatigue load to peak static load at $10^{6} \mathrm{cy}-$ cles are almost equal.

(c) $12.7 \mathrm{~mm}$ lap length and $1.27 \mathrm{~mm}$ adhesive thickness

A total of six fatigue tests were conducted at various load amplitudes for this group of specimens. The fatigue load at $10^{6}$ cycles is estimated as $1.152 \mathrm{kN}$, which is $55.5 \%$ of the peak static load of $2.075 \mathrm{kN}$. The fatigue load at $10^{6}$ cycles for $1.27 \mathrm{~mm}$ adhesive thickness is approximately $14.5 \%$ lower than that for $0.762 \mathrm{~mm}$ adhesive thickness. However, in terms of percentage of the peak static load, they are almost equal.

The failure mode in fatigue was either a fiber tear or a combination of fiber tear and adhesive failure, similar to the ones observed in static tests for 0.762 and $1.27 \mathrm{~mm}$ adhesive thickness. For the combined failure mode, the amount of fiber tear was determined by placing a 10-by-10 square grid pattern on the 25.4 $\mathrm{mm}$ by $25.4 \mathrm{~mm}$ lap area of the failed specimens. A comparison of failed static and fatigue specimens shows that, for the same adhesive thickness, the fatigue specimens have a greater amount of fiber tear. Also, the greater the number of cycles to failure, the greater is the amount of fiber tear.

\section{Residual Strength After Fatigue}

Static tests were performed on specimens that did not fail in fatigue in $3.0 \times 10^{6}$ cycles to determine their residual strengths after fatigue. The results are given in Table 4 . The residual joint strength was close to the average static strength, which indicates that the damage caused by fatigue cycling at lower load levels is relatively small.

Table 4. Residual Load After Fatigue.

\begin{tabular}{|c|c|c|c|c|c|}
\hline $\begin{array}{l}\text { Lap } \\
\text { Length } \\
\text { (mm) }\end{array}$ & $\begin{array}{c}\text { Adhesive } \\
\text { Thickness } \\
\text { (mm) }\end{array}$ & $\begin{array}{c}\text { Fatigue } \\
\text { Load } \\
\text { (\% Avg. } \\
\text { Static Load) }\end{array}$ & $\begin{array}{l}\text { Cycles } \\
\text { Endured }\end{array}$ & $\begin{array}{c}\text { Residual } \\
\text { Load } \\
\text { (\%Avg. } \\
\text { Static Load) }\end{array}$ & Failure Mode(1) \\
\hline 12.7 & 0.762 & $\begin{array}{l}33.6 \\
49.2 \\
49.9 \\
54.2\end{array}$ & $\begin{array}{l}4,000,000 \\
4,184,325 \\
3,204,000 \\
3,413,000\end{array}$ & $\begin{array}{l}62.6 \\
90.7 \\
100 \\
102\end{array}$ & $\begin{array}{l}100 \% \text { FT } \\
100 \% \text { FT } \\
46.6 \% \text { FT, } 53.3 \% \mathrm{ADH} \\
100 \% \text { FT }\end{array}$ \\
\hline 38.1 & 0.762 & $\begin{array}{l}51.9 \\
57.5\end{array}$ & $\begin{array}{l}4,240,000 \\
4,357,000\end{array}$ & $\begin{array}{l}104.5 \\
125.3\end{array}$ & $\begin{array}{l}100 \% \mathrm{FT} \\
100 \% \mathrm{FT}\end{array}$ \\
\hline 12.7 & 1.27 & $\begin{array}{l}55.5 \\
61.9\end{array}$ & $\begin{array}{l}4,959,000 \\
5,000,000\end{array}$ & $\begin{array}{l}115 \\
118.8\end{array}$ & $\begin{array}{l}66.6 \% \mathrm{FT}, 33.7 \% \mathrm{ADH} \\
38.3 \% \mathrm{FT}, 61.7 \% \mathrm{ADH}\end{array}$ \\
\hline
\end{tabular}

(1) FT: fiber tear; $\mathrm{ADH}$ : adhesive failure. 


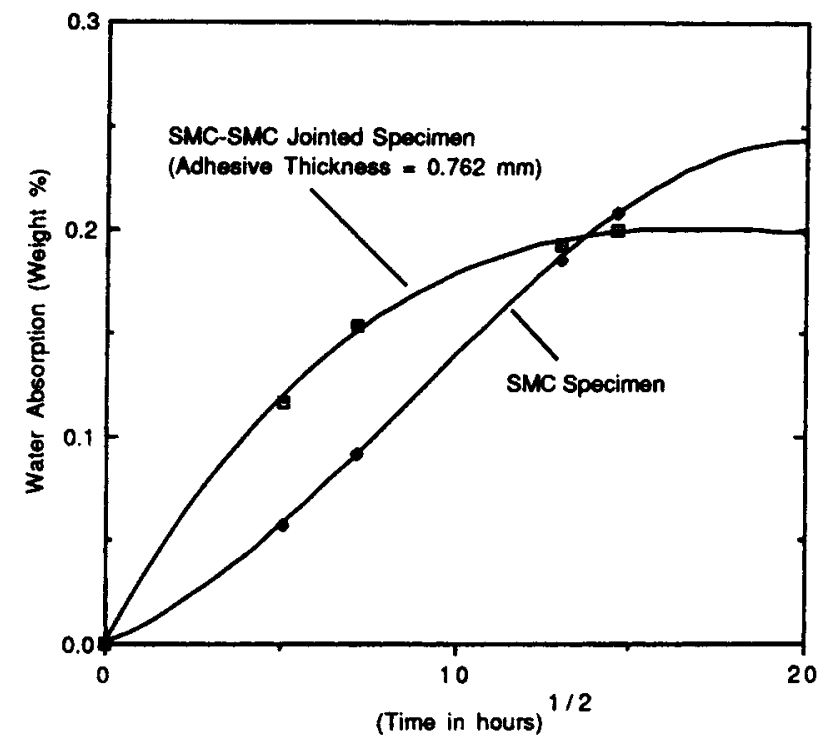

Fig. 7. Water absorption at $23^{\circ} \mathrm{C}$ in SMC-SMC lap joints.

\section{Frort of Water Immerwion on the Fatigue Strength}

In order to determine the effect of water absorption on the joint strength, single lap joints of SMC-SMC substrates were prepared using the first batch of adhesive, weighed and kept immersed in tap water at room temperature $\left(23^{\circ} \mathrm{C}\right)$ for 214 hours (almost 9 days). During this time, specimens were periodically taken out of the water tank, wiped and then weighed in a balance with an accuracy of $0.1 \mathrm{mg}$. To calculate the amount of water absorbed by the adhesive, unbonded SMC specimens were also kept in the water tank and weighed in the similar way. After 214 hours of water immersion, specimens were taken out from the water tank, wiped, weighed and coated with a moisture resistant silicone coating. Both static and fatigue tests were performed with these specimens. The lap length and the adhesive thickness in these specimens were $12.7 \mathrm{~mm}$ and $0.762 \mathrm{~mm}$, respectively.

Water absorption (in weight percent) is shown as a function of square root of time (in hours) in Fig. 7 for SMC-SMC specimens. The water absorption in the unbonded SMC specimens is also shown in Fig. 7. After 214 hours of water immersion, the SMC-SMC specimens absorbed $0.2 \%$ of water and appeared to be achieving the equilibrium moisture concentration. The water absorption in the unbonded specimens lagged behind that in the bonded specimens; however, in 214 hours, they became nearly equal.

Static test results for single lap joint specimens after water immersion show very little effect of water immersion on the peak load and lap shear value. Average peak load of three specimens after 214 hours of water immersion was $2.05 \pm 0.323 \mathrm{kN}$, which is close to the peak load of $2.02 \pm 0.069 \mathrm{kN}$ of unexposed specimens prepared with the same batch of adhesive. Around $80-90 \%$ adhesive failure and 10-20\%

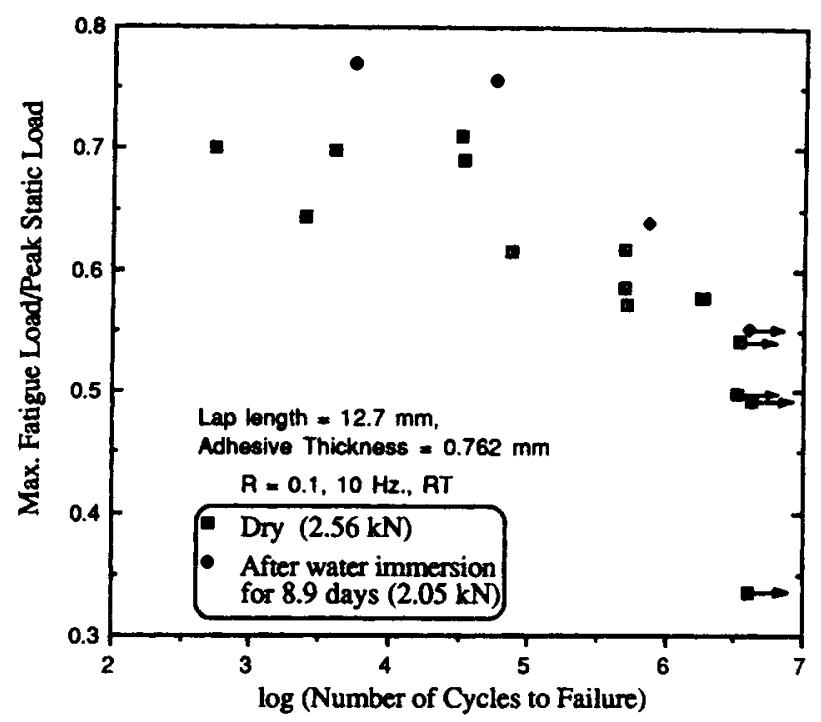

Fig. 8. Fatigue S-N diagram for SMC-SMC lap joints after 214 hours of water immersion.

fiber tear was observed in the exposed specimens. Figure 8 shows the effect of water exposure on the fatigue behavior of SMC-SMC joints. The fatigue strength at $10^{6}$ cycles is $55 \%$ of static strength, which is close to the values for unexposed specimens.

\section{conclusions}

Following conclusions can be made from the static and fatigue tests performed on SMC-SMC single lap joints bonded together with an epoxy adhesive:

1) The static failure load depends on the lap length as well as the adhesive thickness. The maximum failure load was observed at an adhesive thickness of $0.33 \mathrm{~mm}$, whereas it increased with increasing lap length for the three lap lengths investigated here.

2) The static failure load increases with increasing testing speed. The SMC surface preparation by acetone cleaning or sanding did not show any significant difference over the dry wiped surface.

3) The joint failure load also depends on the substrate tensile strength in the direction of loading. The substrate tensile strength in an SMC may not be equal in all directions as was found in the SMC under investigation.

4) Recessed joints with gap between adhesive in the lap area show static failure load that is equal to that for continuous joints. Although this result is promising, it requires further analytical and experimental investigation, which is being continued at the present time.

5) The fatigue strength at $10^{6}$ cycles of single lap SMC-SMC joints is approximately $50 \%$ to $54 \%$ of the static strength. The adhesive thickness or the lap length influence the static strength of the 
joint, they appear to have a very small effect on this ratio.

6) Water immersion for 214 hours does not affect the static failure load. The fatigue strength of water soaked specimens at $10^{6}$ cycles is approximately $55 \%$ of the static strength, which is the same as found for the dry specimens.

\section{ACETHOWLDGWIET}

The authors wish to acknowledge the financial grant provided by the Michigan Materials and Processing Institute and the Automotive Composites Consortium for this project. The authors are particularly thankful to Dr. Jessica Schroeder of the GM Research and Development for her useful comments and encouragement throughout this work.

\section{RDFERENCES}

1. F. L. Matthews, P. F. Kilty, and E. W. Godwin, Composites, 13, 29 (1982).

2. S. J. John, Composites Bonding, ASTM STP 1227, American Society for Testing and Materials, Philadelphia (1994).
3. B. M. Parker, Composites Bonding, ASTM STP 1227, American Society for Testing and Materials, Philadelphia (1994).

4. R. B. Gilmore and S. J. Shaw, Composites Bonding, ASTM STP 1227, American Society for Testing and Materials, Philadelphia (1994).

5. J. G. Dillard and I. M. Spinu, "Durability in Automotive Adhesive Bonding," 39th Intl. SAMPE Symposium, 3143 (1994).

6. A. R. Krause, J. W. Holubka, and W. Chun, "The Effects of Adhesive Chemistry on the Fatigue Resistance of Adhesive Bonds in Service Environment," Advanced Composites: The Latest Developments, ASM/ESD 2nd Conference on Advanced Composites (1986).

7. J. W. Holubka, W. Chun, A. R. Krause, and J. Shyu, "Effects of Corrosive Environments on the Locus and Mechanism of Failure of Adhesive Joints," ACS Symposium Series 322, p. 194, Polymeric Materials for Corrosion Control, R. A. Dickie, and F. L. Floyd, eds., American Chemical Society, Washington, D.C. (1986).

8. T. P. Lang, Stress Analysis and Failure Prediction of Adhesively Bonded Single Lap Joints in Automotive Composites, MS thesis, University of Michgian-Dearborn, Dearborn (1997).

9. T. P. Lang and P. K. Mallick, "The Effect of Recessing on the Stresses in Adhesively Bonded Single Lap Joints," Int. $J$. Adhesion and Adhesives (submitted for publication). 